\title{
p53 activity is selectively licensed in the Drosophila stem cell compartment
}

\author{
Annika Wylie ${ }^{1 \dagger}$, Wan-Jin Lu' ${ }^{2 \dagger}$, Alejandro D'Brot ${ }^{1}$, Michael Buszczak ${ }^{3}$, \\ John M Abrams ${ }^{1 *}$
}

'Department of Cell Biology, University of Texas Southwestern Medical Center, Dallas, United States; ${ }^{2}$ Institute for Stem Cell Biology and Regenerative Medicine, Stanford University School of Medicine, Stanford, United States; ${ }^{3}$ Department of Molecular Biology, University of Texas Southwestern Medical Center, Dallas, United States
*For correspondence: John. Abrams@utsouthwestern.edu

'These authors contributed equally to this work

Competing interests: The authors declare that no competing interests exist.

Funding: See page 14

Received: 13 September 2013 Accepted: 11 February 2014 Published: 11 March 2014

Reviewing editor: Carol Prives, Columbia University, United States

(c) Copyright Wylie et al. This article is distributed under the terms of the Creative Commons Attribution License, which permits unrestricted use and redistribution provided that the original author and source are credited.

\section{Introduction}

Throughout the animal kingdom, p53 occupies a central position within conserved stress response networks. The protein integrates diverse signals associated with DNA damage and uncontrolled proliferation to govern adaptive downstream responses such as increased DNA repair, arrested cell cycle, and apoptosis (Vousden and Lane, 2007). Where examined, the genes encoding p53 are not essential for viability but have been implicated as regulators of aging (Derry et al., 2007; Donehower et al., 1992; Lee et al., 2003; Sogame et al., 2003). It is now well appreciated that ancestral roles for this gene family must have predated functions in tumor suppression. In support of this, members of the p53 gene family are present in unicellular protists and short-lived multicellular organisms (Lu et al., 2009; Mendoza et al., 2003; Nordstrom and Abrams, 2000). Furthermore, cancer was probably a negligible source of selection pressure during the course of human evolution (Aranda-Anzaldo and Dent, 2007) and the combined removal of canonical p53 effectors (p21, Puma, and Noxa) does not account for tumor suppression in mice (Valente et al., 2013). These and other observations suggest that tumor suppressive roles for the p53 family were co-opted from primordial functions, some of which may have been linked to meiotic recombination (Lu et al., 2010).

In recent years, considerable evidence has surfaced linking p53 action to stem cell biology. For example, in mammary stem cells p53 promotes asymmetric division and cell polarity, thereby helping to limit the population of stem cells in the mammary gland (Cicalese et al., 2009). Furthermore, reprogramming of somatic cells into induced pluripotent stem cells (iPSCs) is greatly increased in p53 deficient cells, suggesting that p53 may act as a 'barrier for induced pluripotency' (Krizhanovsky and Lowe, 2009). Consistent with this, several labs have shown that p53 induces embryonic stem cell differentiation to maintain genomic stability after DNA damage (Lin et al., 2005; Neveu et al., 2010; 
eLife digest The most common genetic change seen in cancer patients produces a faulty version of the $\mathrm{p} 53$ protein, which normally restricts tissue growth. This change promotes cancer because cells can now divide faster and fail to die when they should. Much remains to be learned about how p53 functions to restrain growth. As p53 is found in primitive organisms, and cancer is unlikely to have significantly influenced evolution, suppressing tumor formation was almost certainly not the original function of this gene. Furthermore, p53 works in a different way compared to many other tumour suppressors. Therefore, prevention of cancer is likely to have evolved as a side effect derived from more ancient functions.

Recently, a link between p53 and stem cells has been uncovered. Stem cells are special because they can develop into many different types of cells, and they are crucial for the growth and repair of tissues. To form a particular type of cell, the stem cell divides to create two daughter cells. Commonly, one daughter cell stays in the stem state, whereas the other becomes a particular type of cell, such as a nerve cell or muscle cell. Because of this special property, scientists hypothesize that stem cells have special mechanisms to protect them from DNA damage that might partially depend on p53. This would prevent the spread of damaged genomes that would otherwise occur among daughter cells.

To learn more about how p53 influences stem cells, Wylie, Lu et al. monitored its activity in the gonads of fruit flies, which are a powerful genetic model. They found that damaging DNA activates p53 in stem cells and their daughter cells, but not in other types of cells that have been damaged. In addition, p53 is activated by the uncontrolled growth and division of stem cells in the gonad, even when DNA is not damaged. This is unexpected since molecules linking inappropriate growth to p53 were thought to be present only in mammals. Therefore, it appears that the tumorsuppressing behavior of p53 in mammals was adapted from its more ancient ability to regulate stem cell growth-an ability that evolved before organisms divided into vertebrates and invertebrates. DOI: 10.7554/eLife.01530.002

Zhao and $X u, 2010)$. Together with recent studies in planaria, these observations indicate that an ancestral focus of p53 action could operate in stem cells (Pearson and Sanchez Alvarado, 2009). We directly tested this possibility using a p53 biosensor to visualize Drosophila germline stem cells and their progeny. When DNA breaks were exogenously imposed or intrinsically engineered, Drosophila p53 (Dp53) was activated selectively in germline stem cells (GSCs) and their immediate daughters, indicating that these cells are uniquely licensed for p53 action. Furthermore, in various germline tumor models Dp53 was constitutively hyperactivated, suggesting that ancient links between p53 and inappropriate growth predate canonical effectors that connect these regulatory networks (e.g., ARF and MDM2).

\section{Results}

\section{Damage-induced Dp53 activity in the germline is restricted to stem cells}

The Drosophila gonad is a classic system for studying the stem cell compartment since stem cells, their immediate daughters, and the surrounding niche are easily identified. In the ovary, germline stem cells (GSCs) undergo self-renewing divisions that typically produce a GSC and a cystoblast (CB). These GSCs support egg production throughout the lifespan of female adults (Figure 1B). We used in vivo biosensors (Lu et al., 2010; Brodsky et al., 2000) to visualize p53 activity as GSCs responded to various sources of stress (Figure 1A). To exclude technical artifacts, two GFP reporters were used-one localizes to the nucleus (p53R-GFPnls) and the other does not (p53R-GFPcyt). As previously described (Lu et al., 2010), programed p53 activity triggered by meiosis was only observed in region 2 (Figure 1B). After exposure to ionizing radiation (IR) stress, p53 activity was induced in virtually all germaria. However, despite widespread damage to the organ (Figure 1-figure supplement 1), this unprogrammed response was remarkably restricted to germline stem cells (GSCs) and their immediate progeny (CBs) (Figure 1C,E). Furthermore, as seen in Figure 1-source data 1A, this response was highly penetrant. Since we rarely observe reporter activation only in $\mathrm{CBs}$, the signal seen in CBs probably reflects GFP perduring from the parental stem cells. Furthermore, post-irradiation levels of 
A

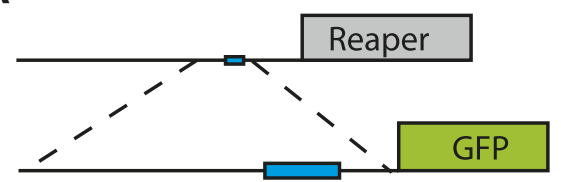

p53R-GFP

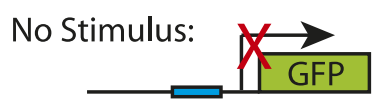

Stress:

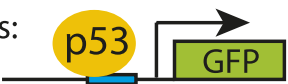

B

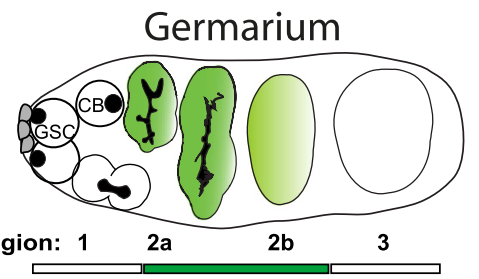

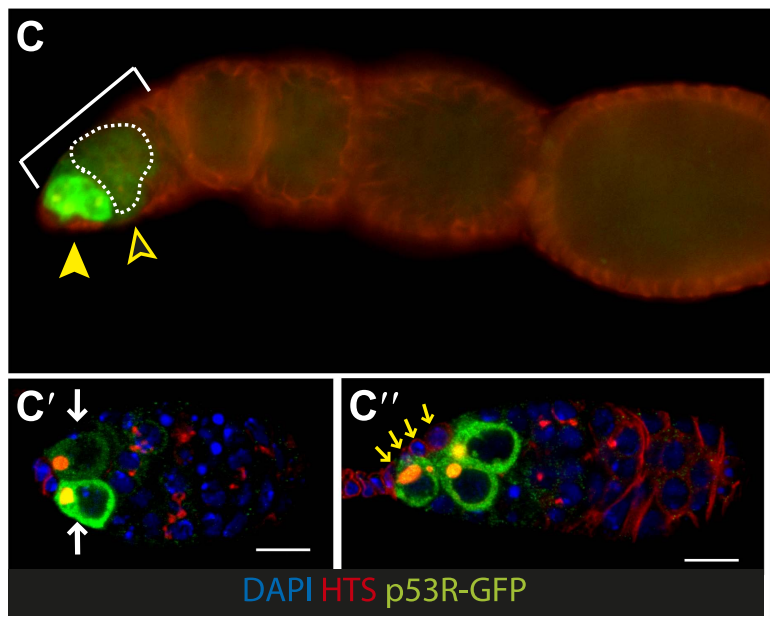
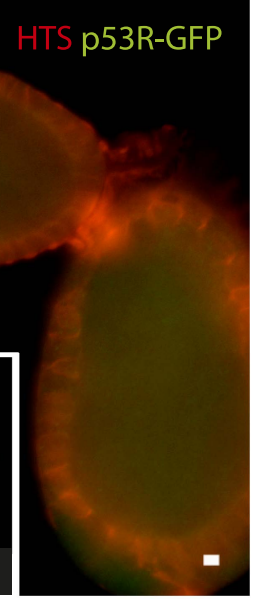

E

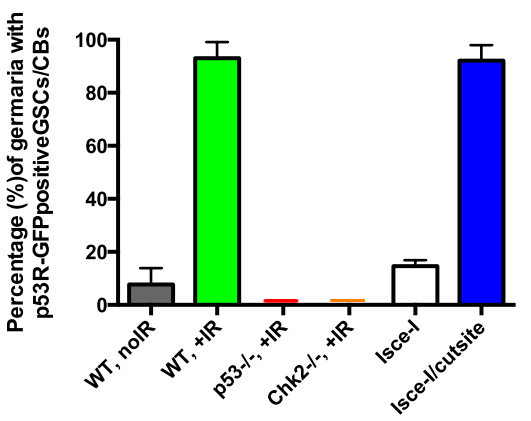

Figure 1. Genotoxic stress selectively triggers p53 activity in ovarian stem cells. (A) Construction of p53 biosensors. A well-characterized p53 enhancer (black line) that contains a p53 consensus binding site (blue box) conserved from flies to humans resides upstream of the reaper locus (gray box) (Brodsky et al., 2000). A 150-bp fragment containing this enhancer was placed upstream of GFP (p53R-GFP). Transgenic fly strains are made with two reporter constructs, one contains a nuclear localization signal for GFP (p53R-GFPnls) and the other one does not (p53R-GFPcyt). Stimuli that trigger p53 activation induce GFP expression. These biosensors require wild-type p53 and are effective readouts for p53 function. (B) Germline stem cells (GSCs) are in contact with cap cells (in gray) at the apical tip of the germarium and undergo self-renewing division to produce a GSC and cystoblast (CBs) (Spradling et al., 2001). In unperturbed ovaries, programed activation of the p53R-GFP biosensor is triggered by meiotic recombination in region 2 of the germarium, marked by open arrowhead in (C) and (D) (Lu et alo, 2010). (C) After radiation challenge (IR) the p53R-GFPcyt biosensor (green) is selectively induced in ovarian GSCs and CBs noted by a solid arrowhead. Bracket denotes the germarium. The open arrowhead and dotted line indicates p53 activation in region 2 prompted by meiosis. Insets $\left(\mathbf{C}^{\prime}\right.$ and $\left.\mathbf{C}^{\prime \prime}\right)$ are confocal images from different irradiated germaria counterstained with DAPI (blue). p53R-GFPcyt induction (green) initiates in GSCs that exhibit rounded fusomes ( $\mathbf{C}^{\prime}$ white arrows) labeled by $\alpha$-HTS (Hu li tai shao, red) and are in contact with cap cells ( $\mathbf{C}^{\prime \prime}$ yellow arrows). Cells that activate p53 in ( $\mathbf{C}^{\prime}$ and $\mathbf{C}^{\prime \prime}$ ) were confirmed to be germ cells by $\mathbf{a}$-Vasa staining (shown in Figure 1-figure supplement 2C-D'). (D) An engineered DNA double-stranded break (DSB) mediated by I-Scel (see texts and 'Materials and methods') induces the p53R-GFPnls biosensor (green) in GSCs/CBs, noted by a solid arrow. Open arrow indicates meiotic p53. The germarium is counterstained with $\alpha$-HTS (red) and DAPI (blue). (E) Quantifies the percentage of germaria activated for the p53 biosensors in GSCs and their immediate progeny. Note that the perturbation-dependent responses reported here are all highly penetrant. Selective activation is IR (green) and I-Scel (blue) dependent at the 0.001 significance level. Note that biosensor activation did not occur in $\mathrm{p} 53^{-/-}$(red) or chk2 $2^{-/-}$(orange) mutants (see Figure 1 -figure supplement $2 \mathbf{A}^{\prime}, \mathbf{A}^{\prime \prime}$ ). Sample sizes are combined from at least two independent trials (available in Figure 1-source data 1). All scale bars represent $10 \mu \mathrm{m}$. In panels $\mathbf{C}-\mathbf{C}^{\prime \prime}$ the p53R-GFPcyt reporter was used. In panel $\mathbf{D}$, the p53R-GFPnls biosensor was used.

DOI: 10.7554/eLife.01530.003

The following source data and figure supplements are available for figure 1:

Source data 1. Validation of the p53R-GFP biosensors.

DOI: 10.7554/eLife.01530.004

Figure supplement 1. Wide-spread DNA breaks after irradiation.

DOI: 10.7554/eLife.01530.005

Figure supplement 2. Selective p53 action in germline stem cells is detected using a p53 biosensor. DOI: 10.7554/eLife.01530.006

Figure supplement 3 . ATR is not rate limiting for p53 activation in the germline.

DOI: 10.7554/eLife.01530.007 
GFP were noticeably more robust than the programed activity during meiosis (compare solid arrows to open arrows in Figure 1C,D) (Lu et al., 2010). As expected, p53 biosensor activity was not observed within the ovary of $\mathrm{p} 53^{-/-}$animals and was also absent from ovaries lacking the upstream Chk2 kinase (Figure 1E, Figure 1-figure supplement $2 A^{\prime}, A^{\prime \prime}$, Figure 1-source data 1A).

Double stranded DNA breaks (DSBs) are responsible for many of the biological effects associated with IR (Ward, 1994). Therefore, to determine whether DSBs are sufficient to induce the p53 reporter, we ubiquitously expressed the I-Scel endonuclease in the germline of flies engineered to harbor a single I-Scel recognition site in each nucleus. As seen with IR exposure, p53 activity occurred only in GSCs/CBs when DSBs were induced (Figure 1D,E, Figure 1-figure supplement 2B, Figure 1source data 1B). Furthermore, it is notable that a single DSB was sufficient to provoke robust p53 activity in GSCs/CBs. Therefore, whether exogenously imposed or intrinsically engineered, DSBs triggered p53 selective activation that was confined to GSCs and their immediate progeny. Furthermore, this stem cell restricted response is clearly under genetic control. For example, in directed tests of chosen mutants we identified a class of lesions that exhibit non-selective p53 action throughout the ovary only after IR challenge (see Figure 1-figure supplement 3, Figure 1-source data 1C). Therefore, p53 is present and potentially functional in all cells of the ovary but, under normal conditions, its action is somehow confined to GSCs and their immediate progeny.

To ask whether this pattern might reflect a general property of germline stem cells, we similarly examined the male gonad. As seen in the ovary, we observed selective p53 reporter activation in GSCs and their immediate progeny (gonioblasts) in irradiated testis (Figure 2). Likewise, stimulus-dependent activity required p53 and was not seen in unchallenged testis (Figure 2C, Figure 2-figure supplement 1A,B, Figure 1-source data 1A). Occasionally, the biosensor was also present in early spermatogonial cysts, perhaps reflecting perduring GFP and/or independent activation associated with dying cells (Figure 2D-D", Figure 2-figure supplement 1D-E'). Collectively, the observations in Figure 1 and Figure 2 demonstrate that selective p53 activation in the stem cell compartment is a general property of germline tissues exposed to genotoxic stress. We note that perturbation-dependent induction of the p53 biosensor in gonadal stem cells was highly penetrant (Figure 1E, Figure 2C). However, like all stress responses, the strength of signal and the number of responding cells were variable from animal to animal (Figure 1C,D, Figure 2D) perhaps reflecting distinct cell cycle dynamics occurring in GSCs at the time of challenge.

\section{Genome instability provokes p53 action in the stem cells}

We tested whether other genome destabilizing factors elicited similar p53 activity in stem cells. To examine the effect of deregulated retrotransposons, we introduced the p53 biosensor into cutoff or aubergine mutant animals. These genes encode essential components of the piwi-associated RNA (piRNA) pathway, acting to silence retrotransposons in the germline (Chen et al., 2007). The corresponding mutants exhibit disregulated retrotransposition, reduced fecundity, and egg shell ventralization (Chen et alo, 2007). Figure 3A shows that in cutoff mutants induction of p53R-GFP occurs exclusively in GSCs and their progeny at a penetrance comparable to irradiated wild-type animals (Figure 3-source data 1). Frequent p53 activation in the germline was similarly observed in the GSCs of aubergine mutants (Figure 3B) and rad54 mutants defective for DNA repair (Figure 3C). However, in contrast to cutoff mutants, the p53 biosensor was not entirely restricted to GSCs/CBs in these mutants (Figure 3-figure supplement 1B,C, Figure 3-source data 1) perhaps reflecting differences in the kinetics of repair that may occur in these different backgrounds (Klattenhoff et al., 2007).

\section{p53 enables recovery from stress-induced sterility and proper exit from proliferative arrest}

In somatic cells, Dp53 promotes stress-induced apoptosis (Sogame et al., 2003). Therefore, we examined the germarium for evidence of cell death by detecting cleaved caspase-3. In the 24-hr period post challenge, over $90 \%$ of GSCs induce the reporter but the average incidence of apoptosis was less than 4\% (Figure 4-figure supplement 1, Figure 4-source data 1A). Furthermore, we did not observe an obvious role for p53 in regulating stem cell numbers in the Drosophila ovary in the presence or absence of stress (Figure 1-source data 1, Figure 4-source data 1A). We also used a-pH2Av immunostaining, the Drosophila counterpart of mammalian pH2AX (Mehrotra and McKim, 2006), to follow the repair of DSBs after IR and found that resolution of these lesions was unaffected in the germaria of p53 mutants (Figure 4-figure supplement 2). Similarly, in BrdU incorporation 

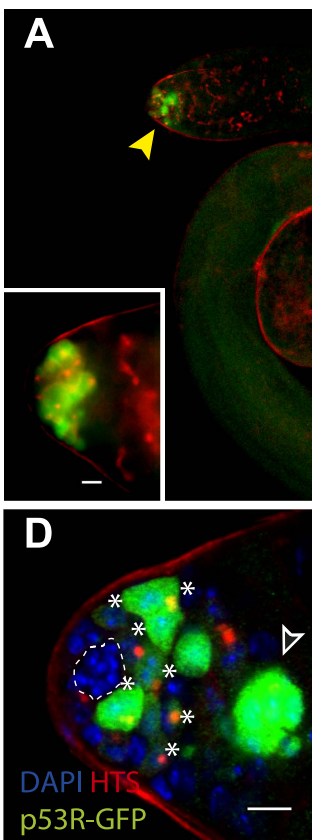

B

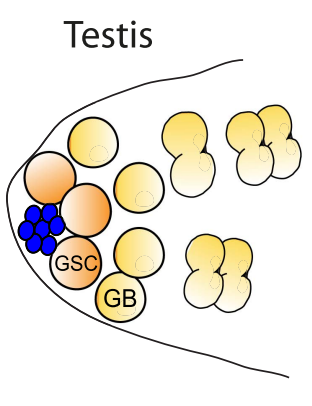

C

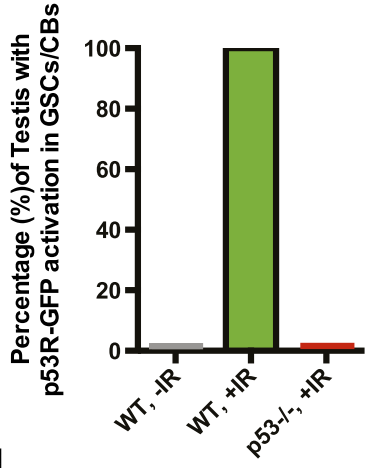

Figure 2. Selective p53 activity occurs in male germline stem cells. (A) p53R-GFPcyt (green) is induced at the apical tip of an irradiated testis (arrowhead), where stem cells are located (see B). $\boldsymbol{\alpha}$-HTS co-staining (red) highlights early stages of germline development. The inset in panel (A) shows a higher magnification view from a different irradiated testis. (B) Male GSCs are in contact with cap cells (blue flower pattern) at the apical tip of the testis and divide to produce a gonioblast daugther (GB). (C) Quantifies the percentage of testis activated for the p53 biosensors in GSCs and their immediate progeny. Selective activation is IR (green) dependent and conditional upon p53 since p53R-GFP activation did not occur in p53-/- mutants (red bar). (D-D") Confocal images from other irradiated testes confirmed that stem cells induced for p53R-GFPcyt (green, $\mathbf{D}$ and $\mathbf{D}^{\prime \prime}$ ) are also positive for rounded HTS staining (red, $\mathbf{D}$ and $\mathbf{D}^{\prime \prime}$ ) and the germline specific marker Vasa (white, $\mathbf{D}^{\prime}$ and $\mathbf{D}^{\prime \prime}$ ) as expected. The hub (dotted line, D) was routinely identified by the characteristic nuclei pattern as illustrated in $\mathbf{B}$ (blue cells) and by negative Vasa staining $\left(\mathbf{D}^{\prime}\right.$ and $\left.\mathbf{D}^{\prime \prime}\right)$. Asterisks mark p53R-GFP positive cells that are adjacent to the hub and Vasa positive or Vasa positive with rounded fusomes. Also note that the hub was identified by a-Armadillo staining (Figure 2-figure supplement $1 C$ ). Open arrowhead in ( $\mathbf{D}$ and $\mathbf{D}^{\prime \prime}$ ) is likely a dying cyst as indicated by pyknotic and condensing nuclei and irregular HTS (Figure 2-figure supplement 1D-E'). In panels A, D-D" the p53R-GFPcyt reporter was used. All scale bars represent $10 \mu \mathrm{m}$.

DOI: 10.7554/eLife.01530.008

The following figure supplements are available for figure 2:

Figure supplement 1. p53 Reporter activation in the male germline (seen in Figure 2A) is conditional upon irradiation (A) and is p53 dependent (B).

DOI: 10.7554/eLife.01530.009

studies, the rates at which wild-type and $\mathrm{p} 53^{-1-}$ GSCs/CBs entered proliferative arrest were also indistinguishable (Figure 4A). However, in the post-stress period, we did observe that p53 mutants were significantly delayed for re-entry into the cell cycle (Figure 4A). Furthermore, this defect is reversed in p53 genomic rescue strains confirming an assignment of this phenotype to the p53 locus (Figure 4source data 1B).

To examine how the action of p53 might coordinate adaptive stress responses in GSCs, we developed a fertility recovery assay. In this study, females were irradiated to induce transient sterility and the recovery of fertility was scored over time (see 'Materials and methods'). Figure 4B shows that wildtype females recovered from infertility within 1 week post-exposure to IR at a dose of $11.5 \mathrm{krad}$. In contrast, females lacking p53 remained permanently infertile even when tracked over 2 weeks after IR (Figure 4B). To confirm that p53 gene function is responsible for this phenotype, we tested $\mathrm{p} 53^{-}$females carrying a genomic rescue fragment spanning the $\mathrm{p} 53$ gene (see 'Materials and methods'). We tested two rescue strains and in both cases the sterility defect was reversed (Figure 4B). 
merge
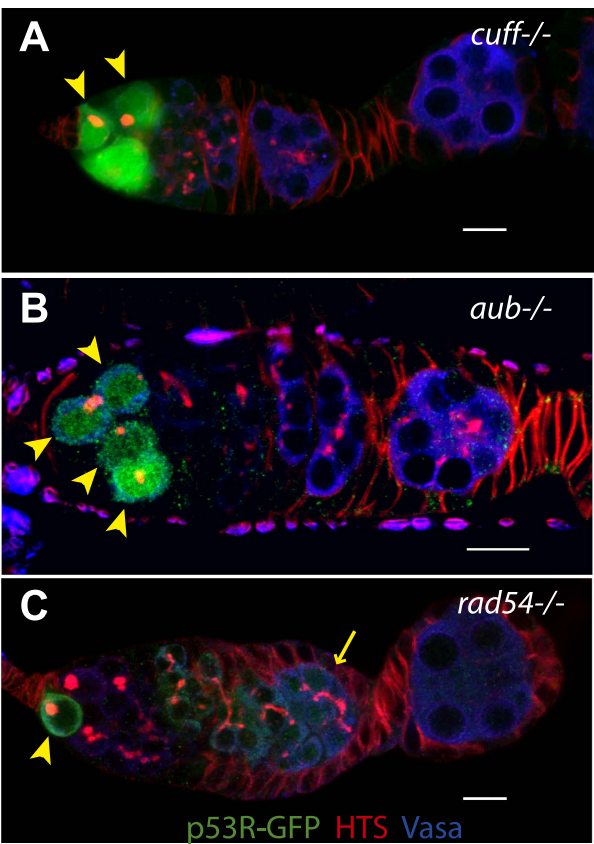

D

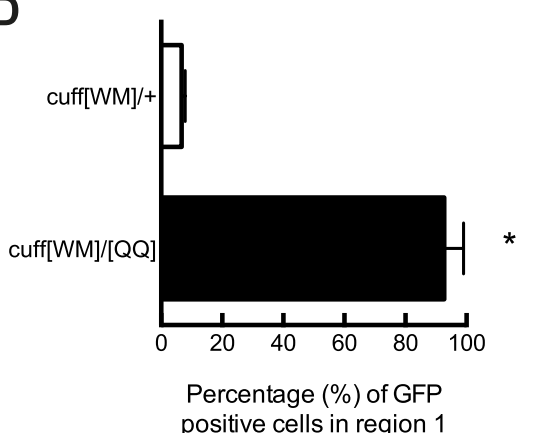

HTS
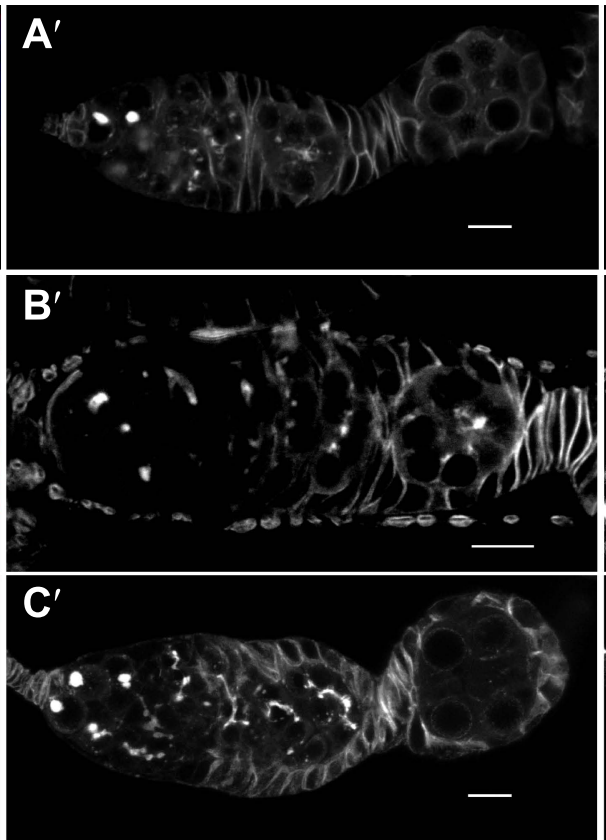

E

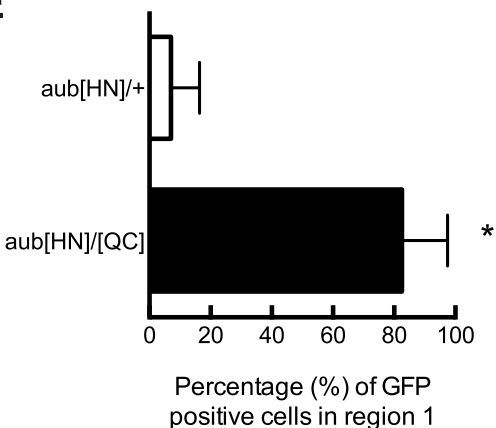

Vasa
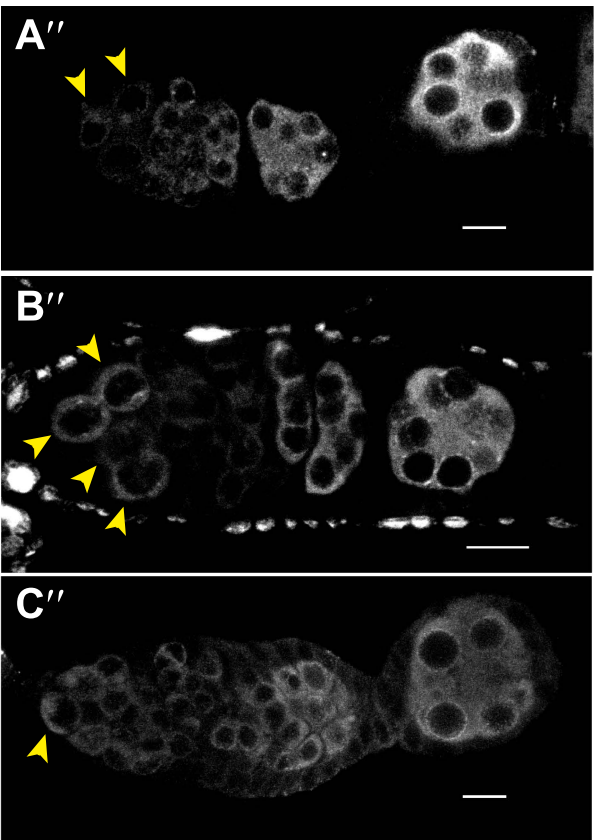

F

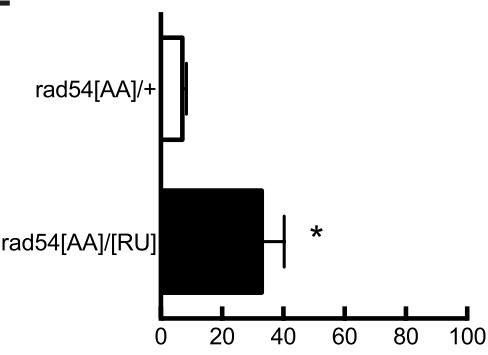

Percentage (\%) of GFP positive cells in region 1

Figure 3. Stem cell associated p53 activity in defective DNA repair and retrotransposon silencing mutants. (A-B) Activation of the p53 biosensor (green) in the germarium of piRNA mutants, (A) cutoff(0)//WM] and (B) aubergine ${ }^{[\mathrm{HN} /[\mathrm{QCC}]}$. (C) Activation of the p53 biosensor in rad54, a meiotic DNA repair mutant. (D-F) Germaria were found to express p53R-GFPcyt in GSCs/CBs with a penetrance of $90 \%$ for cutoff mutants (D, p<0.0001), 80\% for aubergine mutants $(E, p=0.0018)$, and $33 \%$ for rad54 mutants $(F, p=0.0039)$. Asterisks indicate significant differences between heterozygous controls and homozygous mutants. GSCs/CBs were identified by rounded fusomes detected with $\alpha$-HTS (red in merge $\mathbf{A}, \mathbf{B}, \mathbf{C}$ and white in $\mathbf{A}^{\prime}, \mathbf{B}^{\prime}, \mathbf{C}^{\prime}$ ). Arrowheads indicate that p53R-GFP positive cells are also germ cells identified by Vasa staining (blue in $\mathbf{A}, \mathbf{B}, \mathbf{C}$ and white split channel in $\mathbf{A}^{\prime \prime}, \mathbf{B}^{\prime \prime}, \mathbf{C}^{\prime \prime}$ ). Note that this particular $\alpha$-Vasa antibody cross-reacts against the muscle sheath that surrounds each ovariole. If the sheath is not fully dissected and removed, then background staining is evident, as seen in Figure $\mathbf{2 B}^{\prime \prime}$. Control genotypes were cuff(WM] $/ \mathrm{CyO}$, aub $\mathrm{b}^{[\mathrm{HN}]} / \mathrm{CyO}$, rad54[AA]/CyO. Note that aub and rad54 mutants occasionally showed p53 activation beyond region 2 of the germarium (arrow in $\mathbf{C}$ ), quantified in Figure 3-figure supplement 1, Figure 3-source data 1. All scale bars represent $10 \mu \mathrm{m}$. In panels A, B, and C, the p53R-GFPcyt reporter was used. DOI: 10.7554/eLife.01530.010

The following source data and figure supplements are available for figure 3:

Source data 1. Quantification of p53 activation in defective DNA repair and retrotransposon silencing mutants. DOI: 10.7554/eLife.01530.011

Figure supplement 1. Quantification of p53 activation in defective DNA repair and retrotransposon silencing mutants in region 3 and stage 2-8 egg chambers.

DOI: 10.7554/eLife.01530.012 


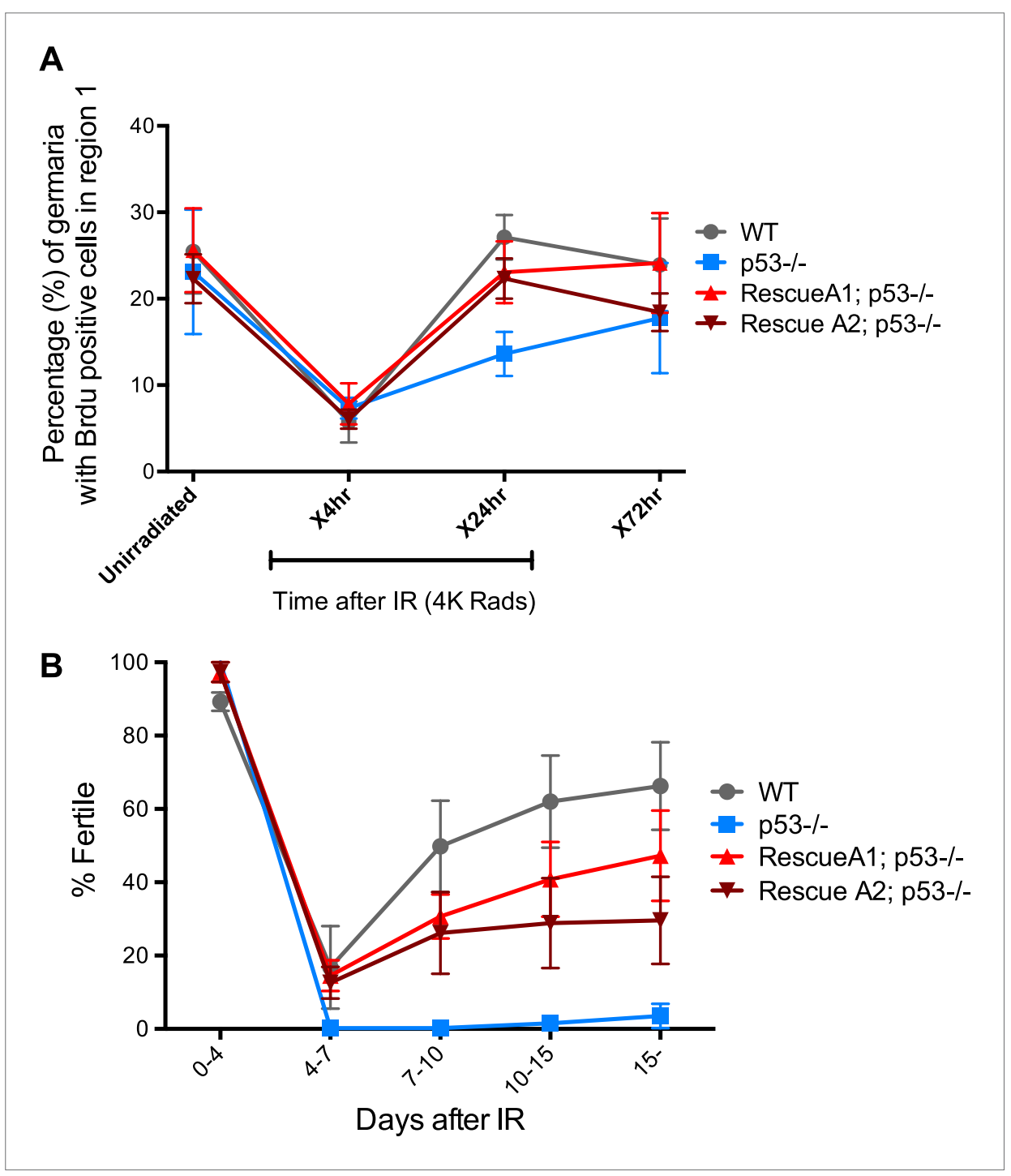

Figure 4. p53 mutants exhibit impaired fertility and delayed re-entry into the cell cycle after irradiation. (A) BrdU incorporation in GSCs after 4 krad of IR. The percentage of germaria containing BrdU positive GSCs/CBs was

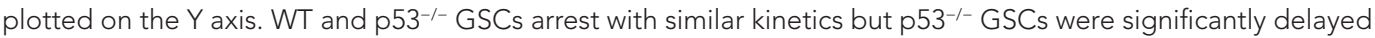
for re-entry into the cell cycle. Error bars represent standard deviation from tests of three independent cohorts. WT and two rescue strains are significantly different from $\mathrm{p} 53^{-/-}$at the 0.05 level at the $\times 24 \mathrm{hr}$ time point. Percentages and number of germaria assayed are included in Figure 4-source data $1 \mathbf{B}$. In panels $\mathbf{A}$ and $\mathbf{B}, \mathrm{p}^{53^{-/}}$represents

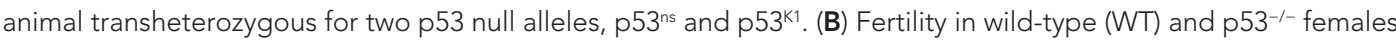
was measured after exposure to $11.5 \mathrm{krad}$ of IR (see 'Materials and methods'), which induces persisting sterility in p53 mutants. WT fertility is significantly different from p53-/- during time points 7-10, 10-15, and 15- at the 0.05 level (see 'Materials and methods'). Two rescue strains showed partial restoration of fertility. Rescue 1A strain showed restored fertility is significantly different from $\mathrm{p} 53^{-/-}$at the 0.05 level at days $10-15$ and 15 -. Note that after 15 days post irradiaton, fertility was monitored for at least 9 more days as indicated by 15-. Error bars represent standard deviation from five independent trials.

DOI: 10.7554/eLife.01530.013

The following source data and figure supplements are available for figure 4:

Source data 1. Quantification of proliferative potential and apoptosis of germaria challenged with irradiation. DOI: 10.7554/eLife.01530.014

Figure supplement 1. Reporter activation after irradiation does not lead to purging of GSCs through apoptosis. DOI: 10.7554/eLife.01530.015

Figure 4. Continued on next page 
Figure 4. Continued

Figure supplement 2. Radiation-induced DNA double-stranded breaks appear and disappear with similar kinetics in WT and $\mathrm{p} 53^{-1-}$ GSCs.

DOI: 10.7554/eLife.01530.016

Figure supplement 3. Fertility recovery correlates with proliferation by GSCs and their progeny. DOI: 10.7554/eLife.01530.017

However, neither rescue strain fully restored fertility to wild type levels, possibly reflecting incomplete restoration of wild type regulation in the transgenes.

To test whether we could link the fertility defect (Figure 4B) to the cell cycle defects observed at a lower dose (Figure 4A), we examined fertility and cell cycle kinetics at an intermediate dose (9 krad) of IR. After this challenge, $\mathrm{p} 53^{-/-}$females exhibit impaired fertility, whereas WT flies remained fertile (Figure 4-figure supplement 3). We performed BrdU incorporation studies over 7 days with females irradiated at $9 \mathrm{krad}$ and assayed the number of germaria that had BrdU positive cells in region 1. Under these conditions, we observed persistently reduced proliferative activity in $\mathrm{p} 53^{-1-}$ stem cells even 7 days after IR (Figure 4-figure supplement 3C, Figure 4-source data 1C). This result is consistent with the possibility that fertility defects seen in $\mathrm{p} 53^{-/-}$flies are linked to the impaired cell cycle kinetics found in GSCs. Furthermore, the data in Figure $4 B$ and Figure 4-figure supplement $3 A$ suggest that radiosensitivity associated with the $\mathrm{p} 53^{-/-}$genotype, previously been documented for larval stages (Sogame et al., 2003), also applies to germline tissue.

\section{Uncontrolled stem cell proliferation activates p53}

Oncogenic properties are thought to simulate 'stemness' and oncogenic signals frequently result in p53 activation (Vousden and Lane, 2007). However, it is not known whether this regulatory axis is conserved beyond mammals. To test whether inappropriate growth triggers Drosophila p53 function, we examined the p53 biosensors in various germline tumor models. First, we expressed an oncogenic form of RAS commonly found in human cancers together with the p53 biosensor (Lee et alo, 1996). Transient expression of the Drosophila Ras ${ }^{\mathrm{V} 12}$ counterpart provoked robust p53 activation mainly in the GSCs and CBs (Figure 5B, Figure 5-source data 1). Figure 5E shows that another oncoprotein, Cyclin E, produced similar results. We also examined these biosensors in bam mutants, where a block in differentiation causes extensive hyperplasia (McKearin and Ohlstein, 1995) and in these tumors extensive reporter activity was also seen (Figure 5C,D). Likewise, expanded BMP (bone morphogenic protein) signaling (Chen and McKearin, 2003) or reduced Lsd1 (lysine-specific demethylase 1) activity (Eliazer et al., 2011) in neighboring somatic cells can also cause inappropriate growth and robust p53 activity was similarly observed in these germline tumors as well (Figure $\mathbf{5 F}, \mathbf{G}, \mathbf{H})$. Therefore, whether caused by forced oncoprotein expression (panels B, E), failed differentiation programs (panels C, D), or expansion of the stem cell niche (panels $\mathrm{F}-\mathrm{H}$ ), inappropriate growth of Drosophila tissues was consistently accompanied by p53 activity. As seen with genotoxic stress, biosensor responses seen in these contexts was somewhat variable, perhaps reflecting complex signaling and/or cell cycle dynamics that occur in these tumor models. Technical sources of variation linked the UAS-GAL4 driver system and/or non-uniform accumulation of the oncogenic product could also contribute to variability in these contexts.

We considered the possibility that inappropriate growth might indirectly activate $\mathrm{p} 53$ by provoking DNA damage. To test this, we stained bam $\Delta^{86}$ ovaries for $\mathrm{pH} 2 \mathrm{Av}$ (Joyce et al., 2011). We observed very few pH2Av foci in bam tumors and, notably, these foci did not co-localize with p53 biosensor activity (Figure 5-figure supplement 1). Therefore, p53 activity in these tumors is not triggered by DSBs but instead, appears to be directly triggered by signals associated with hyperplastic growth.

As seen in Figure 5, diverse types of hyperplastic growth triggered constitutive p53 activity. To ask how p53 functions in these tumors, we examined bam ${ }^{-/-}$ovaries that were either WT or null for p53. Tumor size was not significantly altered in the absence of $\mathrm{p} 53$, but we did observe dramatically altered cytology in tumors that lacked p53. As seen in Figure 6A, bam ${ }^{-/}$ovarian cysts are typically filled with stem-like cells that exhibit round or dumbbell-shaped fusomes when stained with a-HTS (Lin et al.,

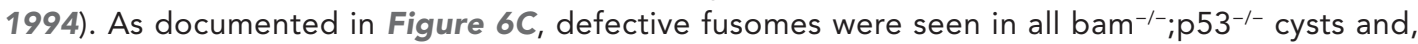
in nearly half of these unusually large nuclei were observed. Though not quantified, micronuclei were also prevalent in these samples. Since defective fusome morphologies and irregular nuclei are 

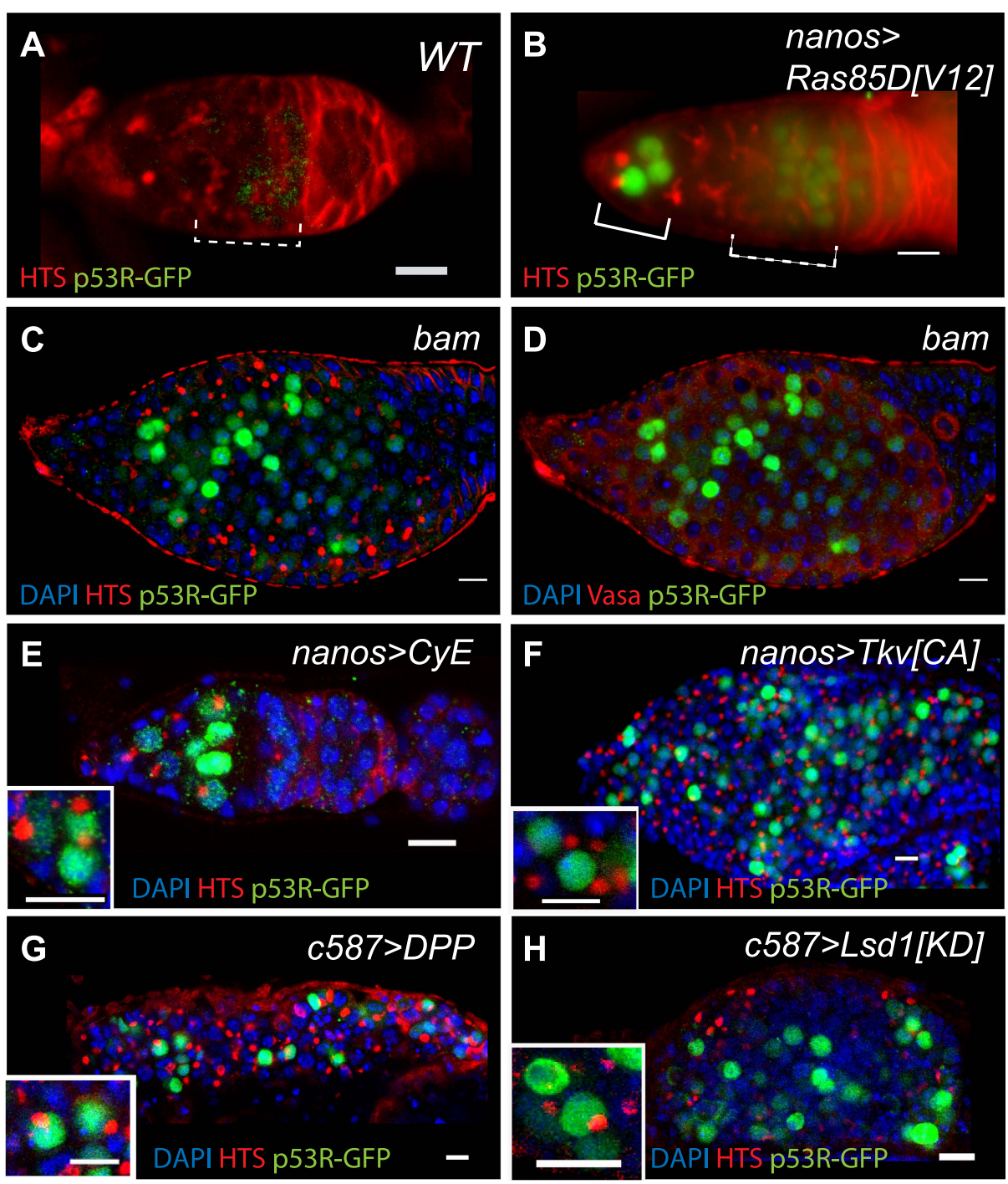

Figure 5. Deregulated growth in the stem cell compartment provokes p53 action. (A) In an unperturbed wild-type (WT) germarium, the p53R-GFPnls biosensor is absent from GSCs/CBs, marked here by rounded fusomes stained with $\alpha$-HTS (red). The modest signal in region 2 reflects meiotic p53 activity (dotted bracket) (Lu et al., 2010). When perturbed by Ras ${ }^{12}$ (B) the p53 biosensor (green) is induced in GSCs/CBs (solid bracket in B, see Figure 5-source data 1). Perturbation from failed differentiation programs caused by the bam mutation (C-D) or Cyclin E over-expression (E) provokes similar p53 biosensor activity. Likewise, increased DPP signaling caused by a constitutively active Tkv receptor (F) or ectopic DPP ligand expression (G) also prompts induction of the p53 reporter. Induction of the p53 reporter is also seen, when the stem cell niche is expanded by silencing of Lsd1 (H) (Eliazer et al., 2011). Insets in panels E-H are magnified views of tumor cysts showing that p53R-GFP positive cells exhibit stem-like properties with rounded fusomes detected by $\alpha$-HTS co-staining (red). Note in panels $\mathbf{B}, \mathbf{E}$ and $\mathbf{F}$, the indicated UAS transgenes were expressed using the germline specific driver, nanosGAL4VP16 (Rorth, 1998). For panels $\mathbf{G}$ and $\mathbf{H}$, expression was achieved by the driver c587-GAL4 in somatic cells of the ovariole tip (Song et al., 2004). All images shown are immunostainings for the p53R-GFPnls biosensor (green), HTS (red), and/or DAPI (blue) except for panel D which was co-stained with $\alpha$-Vasa (red) to show that p53 activated cells retain the germline marker in bam mutants. All other panels (A-C, E-H) were stained with $\mathbf{\alpha}-\mathrm{HTS}$ (red). Note that panel $\mathbf{D}$ stained with $\boldsymbol{\alpha}$-Vasa is the same bam ovariole shown in $\mathbf{C}$ with $\boldsymbol{\alpha}$-HTS. Relevant quantification including the nanosGAL4 driver alone is shown in Figure 5-source data 1. Scale bars $=10 \mu \mathrm{m}$.

DOI: 10.7554/eLife.01530.018

Figure 5. Continued on next page 
Figure 5. Continued

The following source data and figure supplements are available for figure 5:

Source data 1. Quantification of biosensor activity in germline tumors.

DOI: 10.7554/eLife.01530.019

Figure supplement 1. Reporter induction during forced proliferation signals is independent of DNA damage.

DOI: 10.7554/eLife.01530.020

consistent with aberrant mitosis, our data suggests a role for p53 in promoting proper cell cycle progression in these stem-like tumors.

To further examine the functional role of p53 in this context, we examined gene expression profiles of bam ${ }^{-/}$ovaries that were WT or null for p53 by microarray. In total, we found that 297 gene transcripts were altered by at least twofold or greater in the absence of p53. Table 1 lists the top 20 genes that are affected (upregulated or downregulated) by p53 in these tumors. Using the Gene Expression Commons (GEXC) tool, we compared these gene sets to existing germline, embryonic, and somatic expression profiles. We did not find a coherent pattern among the top 20 genes that are normally upregulated by p53. However, among the top 20 genes that are normally suppressed by p53 in these germline tumors, we observed a modest enrichment for transcripts that were absent in either the embryonic stages or other somatic tissues (Table 1-source data 1). These data, together with our histological studies (Figure 6), establish that p53 exerts functional activities that impact cellular and molecular properties of Drosophila stem cell tumors.

\section{Discussion}

We found that adult Drosophila exposed to genotoxic stress or genome destabilizers selectively activated p53 in GSCs and their immediate progeny. This striking specificity was observed despite widespread Dp53 expression (FBgn0039044 m.; Jin et al., 2000; Ollmann et al., 2000) and widespread
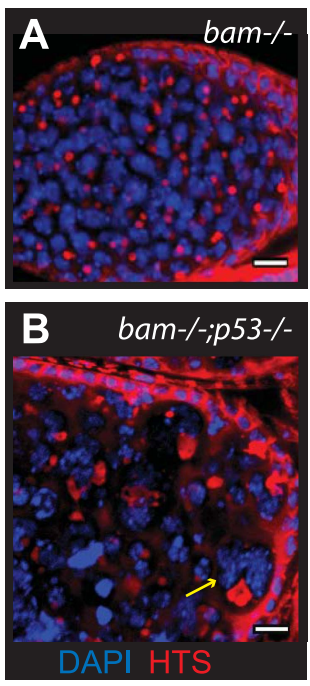

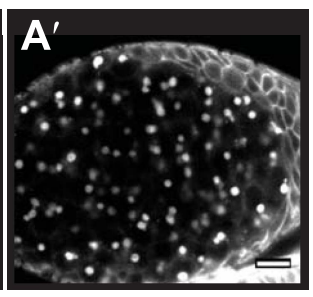

$\mathbf{B}^{\prime}$

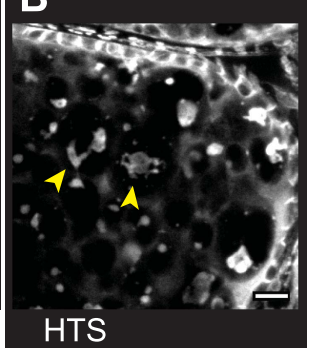

C

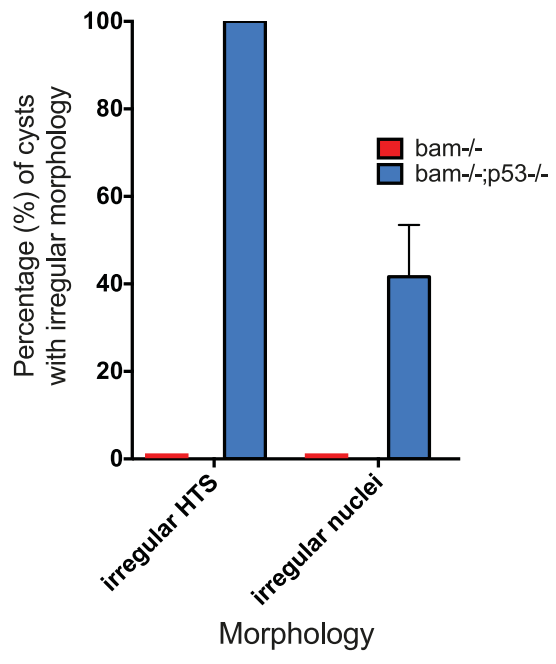

Figure 6. Abnormal fusomes and irregular nuclei are seen in bam ${ }^{-1-} \mathrm{p} 53^{-/-}$tumors. (A-A') Cells in bam ${ }^{-/-}$tumors have rounded fusomes normally associated with the undifferentiated GSC fate. These are detected by $\alpha$-HTS staining (red in $\mathbf{B}$, white in $\mathbf{B}^{\prime}$ ). The nuclei of these cells counterstained with DAPI have diameters less than $10 \mu \mathrm{m}$ (blue in $\mathbf{B}$ ). (B-B') bam ${ }^{-1-} ;$ p53 $^{-/-}$tumors frequently exhibit disorganized fusomes detected here by a-HTS staining (red in $\mathbf{C}_{\text {, }}$ white in $\mathbf{C}^{\prime}$, yellow arrowhead). These tumors also have many fragmented and enlarged nuclei with a diameter significantly greater than $10 \mu \mathrm{m}$ (blue in $\mathbf{C}$, yellow arrow). (C) Quantification of altered fusome structure and irregular nuclei in $\mathrm{bam}^{-/-}$and bam ${ }^{-/-} ; \mathrm{p5}^{-/-}$tumors. Note that in panel $\mathbf{C}$, counts for irregular nuclei do not include micronuclei.

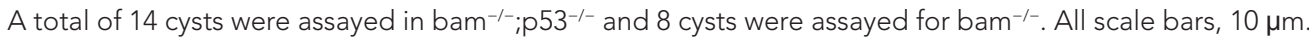
DOI: 10.7554/eLife.01530.021 
Table 1. p53 status impacts expression profiles in bam-/- tumors

\begin{tabular}{lllll}
\multicolumn{7}{l}{ Downregulated by $\mathbf{p 5 3}$} & Upregulated by $\mathbf{5 3}$ & Fold change \\
\hline 1 & Gene symbol & Fold change & Gene symbol & -7.2 \\
\hline 2 & CG31681 & 8.7 & CG31809 & -5.6 \\
\hline 3 & CG5156 & 8.0 & CG31810 & -5.2 \\
\hline 4 & LysX & 7.9 & CG2177 & -5.1 \\
\hline 5 & CG31901 & 7.6 & CG7106 & -4.5 \\
\hline 6 & CG16762 & 7.5 & CG1504 & -4.3 \\
\hline 7 & CG32277 & 7.3 & CG15614 & -4.2 \\
\hline 8 & CG17239 & 7.2 & unpg & -4.2 \\
\hline 9 & CG17012 & 7.1 & CG7329 & -4.1 \\
\hline 10 & CG9897 & 7.1 & CG15236 & -4.1 \\
\hline 11 & Ser12 & 6.8 & CG9294 & -3.9 \\
\hline 12 & CG2191 & 6.8 & esg & -3.7 \\
\hline 13 & CG33258 & 6.6 & Ugt36Ba & -3.6 \\
\hline 14 & CG18125 & CG12780 & CG14297 & -3.6 \\
\hline 15 & CG4783 & 6.5 & CG17129 & -3.6 \\
\hline 16 & Cyp618 & 6.4 & Cyp6a14 & -3.4 \\
\hline 17 & CG17234 & 6.3 & CG5568 & -3.3 \\
\hline 18 & CG18063 & 6.3 & CG1077 & -3.3 \\
\hline 19 & CG9568 & 6.2 & CG11226 & -3.1 \\
\hline
\end{tabular}

We performed microarray analysis on $\mathrm{bam}^{-/-}$and $\mathrm{bam}^{-/-} ; \mathrm{p} 53^{-/-}$tumors. The genes that are altered by $\mathrm{p} 53$ status in $\mathrm{bam}^{-1-}$ tumors are recorded. Listed on the left are the top 20 genes whose abundance is directly or indirectly suppressed by p53. Listed on the right are the top 20 genes whose abundance is directly or indirectly induced by p53. The gene symbol is listed on the left and the fold change in gene expression between $\mathrm{bam}^{-/-}$and

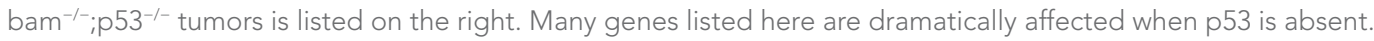
DOI: 10.7554/eLife.01530.022

Source data 1. Expression features of the top 20 genes suppressed by p53. The top 20 genes that were suppressed by p53 in bam-/-;p53-/- tumors (see Table 1) were examined using GEXC (Seita et al., 2012) to identify enriched pathways. Using this collection we observed a mild enrichment for genes that were absent in embryos or absent in adult somatic tissues relative to all genes in the fly genome.

DOI: 10.7554/eLife.01530.023

tissue damage (Figure 1-figure supplement 1). We note that stem cell specificity was not an artifact intrinsic to the biosensors, since independent reporters behaved similarly in both the female and male germline and required the wild-type Dp53 locus in both cases. Furthermore, in certain mutant backgrounds stress-induced activity restricted to GSCs was lost and non-selective p53 activation was widespread throughout the ovary (Figure 1-figure supplement 3B'). Therefore, despite the fact that it is present and activatable throughout the gonad, functional p53 is restricted to stem cells and their immediate progeny by specific genetic determinants.

Collectively, our work supports previous indications that there is an intimate and ancient link between p53 and stem cell biology (Pearson and Sanchez Alvarado, 2009). Our findings also offer rare and novel opportunities to operationally mark the stem cells in the fly germline, as visualized by p53R-GFP. This marker is distinct from conventional stem cell labels (Deng and Lin, 1997) since it is not constitutively expressed but, instead, represents a functional output that is conditional upon a perturbation. We further note that like all reporter systems, our p53 biosensors may not reflect the full scope of effector output regulated by this network, and activities visualized here could transmit only subsets of p53-mediated responses. Nevertheless, despite this possible limitation, our results are consistent with suggestions that stem cells may be acutely sensitive to sources of genomic instability 
with a higher propensity for engaging adaptive responses relative to other cells (Mandal et al., 2011; Sperka et al., 2012). We propose that in reproductive tissues, the p53 regulatory network is either preferentially licensed in stem cells or selectively blocked outside of this compartment.

What upstream regulators might specify p53 activation in GSCs/CBs? Given that stem cells have unique properties, p53 activation in these cells might lie downstream of a novel pathway. Consistent with this idea, ATR expression, was not rate limiting for p53 activation in the germline (Figure 1figure supplement $3 A^{\prime}$, Figure 1-source data 1C). Furthermore, unlike meiotic induction, p53 induction in GSCs/CBs was independent of the topoisomerase, Spo11 (Figure 1-source data 1A; Lu et al, 2010). Chk2 could contribute to the selective activation in stem cells seen here, but since Chk2 is also broadly expressed and functionally associated with oocyte development throughout the ovary (Abdu et al., 2002; Oishi et al., 1998) any potential role in GSCs must extend beyond a simple presence or absence of this kinase.

Our findings also imply stimulus-dependent effectors of p53 in stem cells that are not yet appreciated. For example, within detection limits, we observed no obvious connection between p53 status and apoptosis, DNA double-strand break repair, or cell cycle arrest. However, irradiated $p 53^{-/-}$GSCs were significantly delayed in the re-entry phase for cell cycle. Future studies will explore this defect and also examine progeny derived from stressed GSCs for transgenerational phenotypes that might be adaptive.

Our discovery that p53 action is coupled to hyperplasia in a non-vertebrate species was unexpected for two reasons. First, the role of this gene family as a tumor suppressor is thought to be a derived feature that evolved only in vertebrate lineages. Second, the canonical ARF/MDM2 pathway that links aberrant growth to p53 is absent outside of higher vertebrates (Lu et al., 2009). Surprisingly, our combined results suggest that ancient pathways linking p53 to aberrant stem cell proliferation may predate the divergence between vertebrates and invertebrates.

\section{Materials and methods}

\section{Fly stocks and genetics}

All fly stocks were maintained at $22-25^{\circ} \mathrm{C}$ on standard food media. We obtained rad54, aubergine

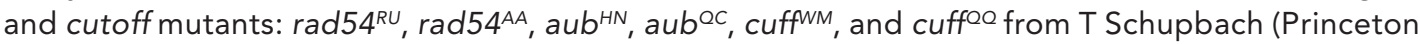
University, Princeton, NJ, USA); c587-GAL4, UAS-dpp, UAS- Lsd1 1KD (Eliazer et al., 2011), homozygous viable allele of bam ${ }^{86}$ (McKearin and Spradling, 1990; McKearin and Ohlstein, 1995), nanosGAL4VP16, and UASp-tkvCA (Chen and McKearin, 2003) have been described previously. All other stocks were obtained from Bloomington Stock Center (Indiana University, Bloomington, IN, USA). The Dp53 rescue strain was engineered by $\phi C 31$ integration of a $20-\mathrm{kb}$ genomic fragment BAC containing the Dp53 locus into an attP site on the X chromosome of the PBac\{y + -attP-9A\}VK00006 line (Bloomington \#9726). The parent BAC CH322-15D03 was obtained from the P[acman] resource library (Venken et al., 2009) and Rainbow Transgenic Flies performed the injection and screening for recombinants. The I-Scel endonuclease strain was generated by K Galindo (Galindo et al., 2009), which was crossed to p53R-GFPnls(STI150); HS-(70Flp)(70 I- Sce I)/TM6 for heat-inducible I-Scel endonuclease expression. Adult females were fattened for 2-3 days after eclosion and then subjected to heat shock in a circulating water bath at $37^{\circ} \mathrm{C}$ for $90 \mathrm{~min}$ and repeated for three consecutive days. $24 \mathrm{hr}$ after the last heat shock, ovaries were dissected for immunostaining. For forced proliferation assays, two GAL4 lines were used: nanos-GAL4VP16 was used to achieve overexpression in the germline with UAS constructs for Ras ${ }^{\mathrm{V} 12}$, CyclinE, and Thickveins (Rorth, 1998). c587-GAL4 was used to achieve overexpression of UAS constructs of Dpp or Lsd1-RNAi in the somatic cells of the ovariole tip (Song et al., 2004). For cyclinE overexpression, stocks were maintained at $25^{\circ} \mathrm{C}$ and female virgins were collected upon eclosion, shifted to $29^{\circ} \mathrm{C}$ for $4-5$ days then subjected to immunostaining. For the Ras ${ }^{\mathrm{v} 12}$ studies, female virgins were shifted to $29^{\circ} \mathrm{C}$ for 1 day and then shifted down to $25^{\circ} \mathrm{C}$ for 3 days prior to immunostaining. The Gal4-UAS system (adapted from yeast) often produces optimal expression at temperatures higher than $25^{\circ} \mathrm{C}$. Since the UAS-Rasv12 and UAS-CyclinE constructs were not optimized for expression in the germline we applied these temperature shifts to produce more penetrant phenotypes.

\section{Irradiation assay}

Well-fed flies were exposed to ionizing radiation using a Cs-137 Mark 1-68A irradiator (JL Shepherd \& Associates, San Ferando, CA, USA) at a dose of 4 krad unless otherwise noted. When irradiating several genotypes, each genotype was placed in an individual vial, and all vials were exposed to IR at 
the same time on a rotating turntable inside the irradiator. For visualizing reporter activation after IR, flies were dissected $24 \mathrm{hr}$ post-IR to allow for stable GFP expression.

\section{Immunostaining of fly tissue}

3- to 5-days-old well-fed females were dissected in PBS and fixed in 4\% EM-grade formaldehyde (Polysciences, Warrington, PA) diluted in PBS-0.1\% tween-20, with three times the volume of heptane. After washing, tissues were blocked in 1.5\% BSA, then incubated with primary antibodies at $4{ }^{\circ} \mathrm{C}$ overnight. Antibodies used: rabbit a-GFP (Invitrogen, Carlsbad, CA); rabbit $\alpha-\mathrm{pH} 2 \mathrm{Av}$ (kindly provided by K McKim with specific staining protocols), rabbit $\alpha$-cleaved caspase 3 (Asp175) (Cell Signaling, Danvers, MA); mouse $\alpha$-Armadillo, mouse $\alpha$-BrdU (Sigma, St. Louis, MO), mouse $\alpha-H T S$ clone 1B1 (Developmental Studies Hybridoma Bank, lowa City, IA), and rat $\alpha$-Vasa (Developmental Studies Hybridoma Bank). For fluorescence visualization, Alexa-488, 568 (Invitrogen), and DyLight 649 (Jackson ImmunoResearch, West Grove, PA) secondary antibodies were used and $0.1 \mu \mathrm{g} / \mathrm{ml}$ of DAPI (Invitrogen) for DNA staining was added in the first wash step. After three washes, ovaries were further hand dissected and mounted in VECTASHIELD (Vector Laboratories, Burlingame, CA) for microscopy imaging. For validating stimulus-dependent p53 action as visualized by the reporters, we routinely confirmed absence of GFP expression using flies null for Dp53. We note that p53R-GFPnls shows constitutive expression independent of p53 in a subset of gut cells and in the region of the testis containing elongated spermatids, reflecting position effects upon this transgene.

\section{Fertility tracking and proliferative arrest assay}

In fertility assays, two p53 null alleles, 238H (ns) and 5A-1-4 (k1) were used in trans-combination to reduce genetic background influences. Two wild-type strains, $y w$ and $w^{1118}$ were used for comparison. p53 rescue transgenes were tested in a transheterozygous $p 53^{-/-}$background ( 1 1; ns/k1 and $A 2$; $\mathrm{ns} / \mathrm{k} 1$ ) to exclude contributions from background modifiers. 5- to 7-day-old females were irradiated at desired doses (11.5 krad for Figure 4B and 9 krad for Figure 4-figure supplement 3) and fertility was tracked over time in groups. Each group contained 10 females and five unirradiated wild-type Canton-S males. The animals were transferred to a new vial at designated time points, and fertility was scored by the presence of larvae 10 days after the parents were removed. Each trial contained 2 to 15 replicates per genotype. For Figure 4B percentages of fertile samples are plotted based on five trials. In the proliferative arrest assay, ovaries were dissected and immersed in Grace's media containing BrdU $(10 \mu \mathrm{M})$ for $1 \mathrm{hr}$ at room temperature. After fixation, ovaries were treated with $2 \mathrm{~N} \mathrm{HCl}$ for 30 min then $100 \mathrm{mM}$ of borax was added for $2 \mathrm{~min}$ to neutralize the $\mathrm{pH}$. Tissues were then processed for blocking and regular immunostaining.

\section{Statistical analysis}

For all statistical analysis, data were placed into GraphPad Prism software. For statistics on the IR and Isce-I reporter activation (Figure 1G, Figure 1-source data 1), one-way ANOVA test was performed on all genotypes with a Tukey's Multiple Comparison post-test. Reporter activation in aubergine, cutoff, and rad54 mutants (Figure 3, Figure 3-source data 1) was analyzed using a two-tailed unpaired t-test comparing the transheterozygous mutant to the heterozygous control. The same analysis was carried out for region 3 and stage 2-8 (Figure 3-figure supplement 1, Figure 3-source data 1). For statistical analysis on fertility and BrdU incorporation assays (Figure 4), one-way ANOVA test was performed for each time point with a Dunnett post-test in which $\mathrm{p} 53^{-1-}$ data was the control. For cleaved-caspase 3 analysis (Figure 4-figure supplement 1), the data was analyzed using a two-tailed unpaired $t$ test. In cases where replicates produce identical values incompatible with the prism two-tailed unpaired t-test tool, one value was negligibly revised to enable computation by this software (e.g., when both values were 0 , one value was changed to $1.0^{\mathrm{e}-12}$ ).

\section{Microarray and Gene Expression Commons (GEXC) analysis}

About 200 ovaries from bam or bamp53 adult females were dissected in batches and pooled together to extract total RNA using Trizol (Invitrogen). After verifying RNA integrity using Bioanalyzer (2100; Agilent), whole-genome expression of each genotype was analyzed using Affymetrix Drosophila Genome 2.0 Array at UTSW Genomics \& Microarray core facility. Microarray data sets were uploaded to Gene Expression Commons (https://gexc.stanford.edu) and analyzed with 17 other public available data sets. In Gene Expression Commons, raw microarray data is individually normalized against a large-scale common reference (for Drosophila genome, $n=2687$ as of Nov 2013), mapped onto the 
probeset meta profile. This strategy enables profiling of absolute expression levels of all genes on the microarray, instead of conventional methods where differences in gene expression are compared only between samples within an individual experiment (Seita et al., 2012).

\section{Acknowledgements}

We thank the following for kindly providing materials: Dr Trudi Schupbach for rad54, aubergine and cutoff mutants, Dr Dennis McKearin for bam, nanos-GAL4VP16, and UASp-TkvCA strains, and Dr Kim McKim for $\alpha-p H 2 A v$ and staining protocols. We thank Dr Susan Eliazer for providing unpublished strains and information. We greatly appreciate Ashley Aguilar for help with dissections and immunohistochemistry and Jessica Alatorre for maintaining fly stocks.

\section{Additional information}

Funding

\begin{tabular}{lll} 
Funder & Grant reference number & Author \\
\hline CPRIT & RP110076 & John M Abrams \\
\hline Ellison Foundation & AG-SS-2743-11 & John M Abrams \\
\hline $\begin{array}{l}\text { National Institute of } \\
\text { General Medical Sciences }\end{array}$ & R01GM072124 & John M Abrams \\
\hline Welch Foundation & I-1727 & John M Abrams \\
\hline Genetics Training Grant & 5T32GM083831 & Annika Wylie \\
\hline $\begin{array}{l}\text { National Institute of } \\
\text { General Medical Sciences }\end{array}$ & GM086647 & Michael Buszczak
\end{tabular}

The funders had no role in study design, data collection and interpretation,

or the decision to submit the work for publication.

Author contributions

AW, W-JL, AD'B, Conception and design, Acquisition of data, Analysis and interpretation of data, Drafting or revising the article; MB, Conception and design, Analysis and interpretation of data, Drafting or revising the article, Contributed unpublished essential data or reagents; JMA, Conception and design, Analysis and interpretation of data, Drafting or revising the article

\section{References}

Abdu U, Brodsky M, Schupbach T. 2002. Activation of a meiotic checkpoint during Drosophila oogenesis regulates the translation of Gurken through Chk2/Mnk. Current Biology: CB 12:1645-1651. doi: 10.1016/S0960-9822(02)01165-X. Aranda-Anzaldo A, Dent MAR. 2007. Reassessing the role of p53 in cancer and ageing from an evolutionary perspective. Mechanisms of Ageing and Development 128:293-302. doi: 10.1016/j.mad.2007.01.001.

Brodsky MH, Nordstrom W, Tsang G, Kwan E, Rubin GM, Abrams JM. 2000. Drosophila p53 binds a damage response element at the reaper locus. Cell 101:103-113. doi: 10.1016/S0092-8674(00)80627-3.

Chen D, McKearin D. 2003. Dpp signaling silences bam transcription directly to establish asymmetric divisions of germline stem cells. Current Biology:CB 13:1786-1791. doi: 10.1016/j.cub.2003.09.033.

Chen D, McKearin DM. 2003. A discrete transcriptional silencer in the bam gene determines asymmetric division of the Drosophila germline stem cell. Development 130:1159-1170.

Chen Y, Pane A, Schüpbach T. 2007. Cutoff and aubergine mutations result in retrotransposon upregulation and checkpoint activation in Drosophila. Current Biology:CB 17:637-642. doi: 10.1016/j.cub.2007.02.027.

Cicalese A, Bonizzi G, Pasi CE, Faretta M, Ronzoni S, Giulini B, Brisken C, Minucci S, Di Fiore PP, Pelicci PG. 2009. The tumor suppressor p53 regulates polarity of self-renewing divisions in mammary stem cells. Cell 138: 1083-1095. doi: 10.1016/j.cell.2009.06.048.

Deng W, Lin H. 1997. Spectrosomes and fusomes anchor mitotic spindles during asymmetric germ cell divisions and facilitate the formation of a polarized microtubule array for oocyte specification in Drosophila. Developmental Biology 189:79-94. doi: 10.1006/dbio.1997.8669.

Derry WB, Bierings R, van lersel M, Satkunendran T, Reinke V, Rothman JH. 2007. Regulation of developmental rate and germ cell proliferation in Caenorhabditis elegans by the p53 gene network. Cell Death and Differentiation 14:662-670. doi: 10.1038/sj.cdd.4402075.

Donehower LA, Harvey M, Slagle BL, McArthur MJ, Montgomery CA Jnr, Butel JS, Bradley A. 1992. Mice deficient for p53 are developmentally normal but susceptible to spontaneous tumours. Nature 356:215-221. doi: 10.1038/356215a0. 
Eliazer S, Shalaby NA, Buszczak M. 2011. Loss of lysine-specific demethylase 1 nonautonomously causes stem cell tumors in the Drosophila ovary. Proceedings of the National Academy of Sciences of the United States of America 108:7064-7069. doi: 10.1073/pnas.1015874108.

FBgn0039044, m. TED. f, modENCODE Temporal Expression Data for FBgn0039044 in Flybase.

Galindo KA, Lu WJ, Park JH, Abrams JM. 2009. The Bax/Bak ortholog in Drosophila, Debcl, exerts limited control over programmed cell death. Development 136:275-283. doi: 10.1242/dev.019042.

Hay B, Jan LY, Jan YN. 1990. Localization of vasa, a component of Drosophila polar granules, in maternal-effect mutants that alter embryonic anteroposterior polarity. Development 109:425-433.

Jin S, Martinek S, Joo WS, Wortman JR, Mirkovic N, Sali A, Yandell MD, Pavletich NP, Young MW, Levine AJ. 2000. Identification and characterization of a p53 homologue in Drosophila melanogaster. Proceedings of the National Academy of Sciences of the United States of America 97:7301-7306. doi: 10.1073/ pnas.97.13.7301.

Joyce EF, Pedersen M, Tiong S, White-Brown SK, Paul A, Campbell SD, McKim KS. 2011. Drosophila ATM and ATR have distinct activities in the regulation of meiotic DNA damage and repair. The Journal of Cell Biology 195:359-367. doi: 10.1083/jcb.201104121.

Klattenhoff C, Bratu DP, McGinnis-Schultz N, Koppetsch BS, Cook HA, Theurkauf WE. 2007. Drosophila rasiRNA pathway mutations disrupt embryonic axis specification through activation of an ATR/Chk2 DNA damage response. Developmental Cell 12:45-55. doi: 10.1016/j.devcel.2006.12.001.

Krizhanovsky V, Lowe SW. 2009. Stem cells: the promises and perils of p53. Nature 460:1085-1086. doi: 10.1038/4601085a.

Lee JH, Lee E, Park J, Kim E, Kim J, Chung J. 2003. In vivo p53 function is indispensable for DNA damageinduced apoptotic signaling in Drosophila. FEBS Letters 550:5-10.

Lee T, Feig L, Montell DJ. 1996. Two distinct roles for Ras in a developmentally regulated cell migration. Development 122:409-418.

Lin T, Chao C, Saito S, Mazur SJ, Murphy ME, Appella E, Xu Y. 2005. p53 induces differentiation of mouse embryonic stem cells by suppressing Nanog expression. Nature Cell Biology 7:165-171. doi: 10.1038/ncb1211.

Lin H, Yue L, Spradling AC. 1994. The Drosophila fusome, a germline-specific organelle, contains membrane skeletal proteins and functions in cyst formation. Development 120:947-956.

Lu WJ, Chapo J, Roig I, Abrams JM. 2010. Meiotic recombination provokes functional activation of the p53 regulatory network. Science 328:1278-1281. doi: 10.1126/science.1185640.

Lu W-J, Amatruda JF, Abrams JM. 2009. p53 ancestry: gazing through an evolutionary lens. Nature Reviews Cancer 9:758-762. doi: 10.1038/nrc2732.

Mandal PK, Blanpain C, Rossi DJ. 2011. DNA damage response in adult stem cells: pathways and consequences. Nature Reviews Molecular Cell Biology 12:198-202. doi: 10.1038/nrm3060.

McKearin D, Ohlstein B. 1995. A role for the Drosophila bag-of-marbles protein in the differentiation of cystoblasts from germline stem cells. Development 121:2937-2947.

McKearin DM, Spradling AC. 1990. bag-of-marbles: a Drosophila gene required to initiate both male and female gametogenesis. Genes \& Development 4:2242-2251.

Mehrotra S, McKim KS. 2006. Temporal analysis of meiotic DNA double-strand break formation and repair in Drosophila females. PLOS Genetics 2:e200. doi: 10.1371/journal.pgen.0020200.

Mendoza L, Orozco E, Rodríguez MA, García-Rivera G, Sánchez T, García E, Gariglio P. 2003. Ehp53, an Entamoeba histolytica protein, ancestor of the mammalian tumour suppressor p53. Microbiology 149:885-893.

Neveu P, Kye MJ, Qi S, Buchholz DE, Clegg DO, Sahin M, Park IH, Kim KS, Daley GQ, Kornblum HI, Shraiman BI, Kosik KS. 2010. MicroRNA profiling reveals two distinct p53-related human pluripotent stem cell states. Cell Stem Cell 7:671-681. doi: 10.1016/j.stem.2010.11.012.

Nordstrom W, Abrams JM. 2000. Guardian ancestry: fly p53 and damage-inducible apoptosis. Cell Death and Differentiation 7:1035-1038. doi: 10.1038/sj.cdd.4400766.

Oishi I, Sugiyama S, Otani H, Yamamura H, Nishida Y, Minami Y. 1998. A novel Drosophila nuclear protein serine/threonine kinase expressed in the germline during its establishment. Mechanisms of Development 71:49-63.

Ollmann M, Young LM, Di Como CJ, Karim F, Belvin M, Robertson S, Whittaker K, Demsky M, Fisher WW, Buchman A, Duyk G, Friedman L, Prives C, Kopczynski C. 2000. Drosophila p53 is a structural and functional homolog of the tumor suppressor p53. Cell 101:91-101. doi: 10.1016/S0092-8674(00)80626-1.

Pearson BJ, Sanchez Alvarado A. 2009. A planarian p53 homolog regulates proliferation and self-renewal in adult stem cell lineages. Development 137:213-221. doi: 10.1242/dev.044297.

Rorth P. 1998. Gal4 in the Drosophila female germline. Mechanisms of Development 78:113-118.

Seita J, Sahoo D, Rossi DJ, Bhattacharya D, Serwold T, Inlay MA, Ehrlich LI, Fathman JW, Dill DL, Weissman IL. 2012. Gene expression commons: an open platform for absolute gene expression profiling. PLOS ONE 7:e40321. doi: 10.1371/journal.pone.0040321.

Sogame N, Kim M, Abrams JM. 2003. Drosophila p53 preserves genomic stability by regulating cell death. Proceedings of the National Academy of Sciences of the United States of America 100:4696-4701. doi: 10.1073/ pnas. 0736384100.

Song X, Wong MD, Kawase E, Xi R, Ding BC, McCarthy JJ, Xie T. 2004. Bmp signals from niche cells directly repress transcription of a differentiation-promoting gene, bag of marbles, in germline stem cells in the Drosophila ovary. Development 131:1353-1364. doi: 10.1242/dev.01026.

Sperka T, Wang J, Rudolph KL. 2012. DNA damage checkpoints in stem cells, ageing and cancer. Nature Reviews Molecular Cell Biology 13:579-590. doi: 10.1038/nrm3420. 
Spradling A, Drummond-Barbosa D, Kai T. 2001. Stem cells find their niche. Nature 414:98-104. doi: 10.1038/35102160.

Valente LJ, Gray DH, Michalak EM, Pinon-Hofbauer J, Egle A, Scott CL, Janic A, Strasser A. 2013. p53 efficiently suppresses tumor development in the complete absence of its cell-cycle inhibitory and proapoptotic effectors p21, Puma, and Noxa. Cell Reports 3:1339-1345. doi: 10.1016/j.celrep.2013.04.012.

Venken KJ, Carlson JW, Schulze KL, Pan H, He Y, Spokony R, Wan KH, Koriabine M, de Jong PJ, White KP, Bellen HJ, Hoskins RA. 2009. Versatile P[acman] BAC libraries for transgenesis studies in Drosophila melanogaster. Nature Methods 6:431-434. doi: 10.1038/nmeth.1331.

Vousden KH, Lane DP. 2007. p53 in health and disease. Nature Reviews Molecular Cell Biology 8:275-283. doi: $10.1038 / \mathrm{nrm} 2147$.

Ward JF. 1994. The complexity of DNA damage: relevance to biological consequences. International Journal of Radiation Biology 66:427-432. doi: 10.1080/09553009414551401.

Zhao T, Xu Y. 2010. p53 and stem cells: new developments and new concerns. Trends in Cell Biology 20:170-175. doi: 10.1016/j.tcb.2009.12.004. 